DR NOEL ELZBIETA RADWANSKI (Orcid ID : 0000-0002-1318-7666)

Article type : Scientific Paper

\title{
Longitudinal evaluation of immunological responses to allergen-specific immunotherapy in horses with IgE associated dermatological disease, a pilot study
}

Noel E. Radwanski ${ }^{\star}$ Daniel O. Morrist, Raymond C. Boston†, Rosario Cerundoloł, Kenneth W. Lee§

* Blue Pearl Veterinary Partners, 3000 Busch Lake Blvd, Tampa, FL 33614, USA;

†School of Veterinary Medicine, University of Pennsylvania, 3900 Spruce St, Philadelphia, PA 19104, USA;

‡Dick White Referrals Veterinary Specialist Centre, Six Mile Bottom, Cambridgeshire, CB8 OUH, UK;

§Greer Laboratories, Inc., 639 Nuway Circle NE, Lenoir, NC 28645, USA.

Running head Longitudinal evaluation of ASIT in horses

Correspondence Noel E. Radwanski E-mail: nradwanski@gmail.com

Source of Funding Greer Laboratories Inc performed the ELISA.

Conflicts of Interest Kenneth W. Lee is an employee of Greer Laboratories Inc. The remaining authors do not have any conflict of interest

This study was presented at the World Congress of Veterinary Dermatology, 2012, Vancouver, Canada. Vet Dermatol 2012; 23 (Suppl 1): 42 .

\section{Abstract}

Background The long-term effects of allergen specific immunotherapy (ASIT) on This is the author manuscript accepted for publication and has undergone full peer review but has not been through the copyediting, typesetting, pagination and proofreading process, which may lead to differences between this version and the Version of Record. Please cite this article as doi: 10.1111/VDE.12732

This article is protected by copyright. All rights reserved 
concentrations of circulating immunoglobulin $E(\lg E)$ and immunoglobulin $G(\lg G)$ in horses has not been reported.

Objectives To document changes in clinical severity of horses with atopic dermatitis (AD) and to monitor allergen-specific IgE and IgG concentrations during a two-year course of ASIT.

Animals Nineteen client-owned horses with a conditional diagnosis of $A D$.

Methods Three ASIT groups were randomly assigned based upon results obtained by either intradermal testing (IDT) for regional allergens $(n=7)$; enzyme-linked immunosorbent assay (ELISA) for specific $\lg E(n=6)$; or a composite of results from both tests $(n=6)$. Serum concentrations of $\mathrm{IgE}$ and IgG specific for allergens included in ASIT were measured at time zero and at four-month intervals. A visual analog scale (VAS) was used to record severity of clinical signs at times zero, 12 and 24 months.

Results Positive correlations were documented between IgE and both immediate and delayed IDT results $(p<0.00001)$, and between immediate IDT and IgG results $(p=0.003)$. Specific IgE in sera decreased significantly $(p<0.05)$ for allergens that were included in ASIT, whereas IgG increased. Across all horses, the mean VAS score decreased by 1.2 units [ $95 \% \mathrm{Cl}: 1.28,1.14$; $(p<0.0001)$ ] during each 12 -month period of ASIT therapy. Improvement in clinical signs was noted in $76.5 \%$ of the horses following 12 months of ASIT and in $82 \%$ after 24 months on ASIT.

Conclusions and clinical importance In this pilot study, ASIT in horses with AD provided significant clinical benefit associated with a concomitant reduction of allergen-specific IgE and elevation of IgG.

\section{Introduction}

Immunoglobulin-E ( $\mathrm{gEE})$ antibodies are known to play an important role in hypersensitivity disorders of horses. ${ }^{1-3}$ Diseases such as insect hypersensitivity $(I H)$, atopic dermatitis $(A D)$ and recurrent airway obstruction appear to be mediated, at least in part, by allergen-specific IgE. The identification of equine IgG and role for IgG in equine hypersensitivity disorders has also been postulated, ${ }^{4-8}$ although its pathomechanism has yet to be fully elucidated.

The most commonly used method to identify the specific allergens responsible for immediate hypersensitivity reactions in horses is the intradermal test (IDT). This test utilizes crude extracts of environmental substances (e.g. pollens, moulds, epithelial extracts, insects) which are injected into the dermis at pre-determined concentrations and volumes for determination of a wheal-and-flare response to each allergen. Injection site responses are typically measured at 30 minutes and four hours post-injection in horses.

Serological assays based on enzyme-linked immunosorbent assay (ELISA) methods are available to equine practitioners for the identification of serum allergen-specific IgE. The clinical

This article is protected by copyright. All rights reserved 
validity of these assays has been questioned due to poor correlation with IDT results. ${ }^{9-11}$ None of the assays have been fully characterized in peer reviewed published studies. Despite these defined limitations, a retrospective study of horses found no significant difference in the clinical response rate to allergen-specific immunotherapy (ASIT), regardless of the test modality on which the allergen vaccine formulation was based. ${ }^{12}$ To date, these results have not been corroborated with prospective clinical trials.

Allergen-specific immunotherapy is the practice of administering gradually increasing quantities of an allergenic extract to an allergic patient with the intent to ameliorate the adverse consequences associated with subsequent exposure to the causative allergen. Although the exact mechanism whereby ASIT effectively controls allergy is not fully understood, it is believed to work, in part, by altering the $T_{H} 1 / T_{H} 2 / T_{H} 17$ and Treg balance which effectively regulates the immune response to subsequent allergen exposure. ${ }^{13}$ To the best of the authors' knowledge, the effect of ASIT on circulating allergen-specific IgE and IgG in horses, throughout the course of ASIT, has not been reported.

The primary objective of the present study was to monitor the sera concentrations of allergenspecific IgE and IgG throughout the course of ASIT. We hypothesized that a favourable clinical outcome would be correlated with a decrease in allergen-specific IgE and an increase in allergen-specific IgG concentrations. The secondary objective was to evaluate the clinical response of horses to ASIT in order to make a comparative assessment of the testing modality used to formulate the ASIT (IDT results versus serum allergen-specific IgE concentrations) based on subsequent clinical outcomes.

\section{Methods and materials}

\section{Animals}

Client-owned horses with a conditional diagnosis of_AD were recruited via advertisement from the north east region of the United States. The Institutional Animal Care and Use Committee (approval \# 802109) approved all aspects of the study and owners signed informed consent forms. The enrolment period took place during our location's peak pollen season (May to September) when seasonally affected horses were exhibiting peak clinical signs.

To be included in the study, horses were required to have a history of pruritus, with or without recurrent urticaria, that flared on a seasonal basis (changing from winter, spring, summer or fall) or pruritus that occurred perennially with repeatable seasonal exacerbations (changing from winter to spring, summer or fall). One of the authors examined all of the horses. Horses were excluded if dermatophytosis, bacterial folliculitis, ectoparasites or haematological and biochemical abnormalities were detected. To be enrolled, horses were required to react to at 
least two non-insect allergens on IDT. Horses only showing positive reactions to biting fly allergens were excluded; however, horses reactive to biting fly allergens in addition to environmental and aeroallergens were included in the study. For these horses, strict insect avoidance strategies were implemented for the duration of the study and biting fly allergens were added to the ASIT based on reactivity. Although adverse reactions to foods (ARF) could contribute to similar clinical signs as $A D,{ }^{14}$ or act in an additive manner to increase the pruritic threshold, concurrent reactions to food were not specifically ruled out for horses with seasonally exacerbated perennial signs.

Horses were prohibited from having received any topical or systemic anti-histamine, topical corticosteroid or oral essential fatty acid therapy for a minimum of two weeks, and systemic corticosteroids for a minimum of four weeks prior to enrolment. However, once ASIT was initiated, concurrent anti-pruritic treatments were permitted for the duration of the study when owners felt symptomatic treatment was necessary. Four horses were included in the study which were previously tested using serological allergen testing and had received ASIT with no clinical improvement. For these horses, immunotherapy had been stopped for at least three months prior to enrolment into the study.

\section{Intradermal test (IDT)}

Horses were sedated with intravenous detomidine $(0.03 \mathrm{mg} / \mathrm{kg})$, and a $30 \times 15 \mathrm{~cm}$ rectangular area on the lateral neck, above the jugular groove and half way between the mandible and shoulder, was clipped with a no. 40 blade. The IDT panel consisted of 82 allergens which were provided by Greer Laboratories (Lenoir, NC, USA) and were administered at concentrations recommended by the manufacturer. The allergens included 14 fungi, 14 grass pollens, 15 tree pollens, 14 weed pollens, five mites, 10 insects and eight environmental allergens/epithelials prevalent in the northeast United States (Table S1). Histamine phosphate $(0.275 \mathrm{mg} / \mathrm{ml}$ ) and the phosphate-buffered saline diluent were used as positive and negative controls, respectively. To ensure consistency in procedure and assessment of reactions, a single investigator performed all IDTs. Approximately $0.1 \mathrm{ml}$ of each allergen was injected in the dermis with a 27 gauge needle.-Injection sites were evaluated by the primary investigator at 30 minutes and 4 hours post-injection. Reactions were interpreted to be positive if the wheal size was greater than or equal to the averaged diameters of the positive (histamine) and negative (saline) controls.

\section{Allergen serology test}

Sera were collected from each horse at the time of enrolment in the study and at four month intervals during the course of ASIT. The laboratory personnel remained blinded to the results of IDT and to which treatment group the horse was assigned for the duration of the study. 
Samples for sera allergen specific-IgE from time point zero were run at time of submission. Subsequent sera submitted were stored frozen at $-20 \stackrel{\circ}{C}$ until conclusion of the study. At the conclusion of the study, the serum samples that were collected at time points zero, four, eight, 12, 16, 20 and 24 months were evaluated separately for IgE and IgG reactivity to the panel of allergens provided by Greer Laboratories (Lenoir, NC, USA). To ensure consistency of results, all samples were evaluated for either IgE or IgG reactivity within single run.

Buffers: The buffers used throughout have been previously described ${ }^{15,16}$ and included: a) well coating buffer: $0.05 \mathrm{M}$ sodium carbonate bicarbonate buffer, $\mathrm{pH} 9.6$; b) wash buffer: phosphate buffered saline (PBS), $\mathrm{pH} 7.4$, containing $0.05 \%$ Tween 20 , and $0.05 \%$ sodium azide; c) serum and reagent diluent buffer: PBS, pH 7.4, containing $1 \%$ fish gelatin, $0.05 \%$ Tween 20 and $0.05 \%$ sodium azide.

Preparation of coated wells: Immulon $4 \mathrm{HBH}$ flat bottom strip assemblies (Thermo Electron Corporation, Waltham, MA, USA) were used throughout and served as the solid phase for all direct bind ELISA. The twelve well strips were individually coated with the specified allergen extracts following a previously reported procedure. ${ }^{15,16}$ Briefly, the individual extracts were diluted in bicarbonate buffer $(\mathrm{pH}$ 9.6) and $100 \mu \mathrm{L}$ was added to each assigned well. Following overnight incubation at $4-8{ }^{\circ} \mathrm{C}$, the wells were washed with PBS, blocked with $1 \%$ monoethanolamine ( $\mathrm{pH} 7.5)$ then air dried and stored at $4-8{ }^{\circ} \mathrm{C}$ in Ziploc ${ }^{\mathrm{TM}}$ bags until used.

\section{Calibrators}

Calibrator solutions of predetermined reactivity in ELISA for both IgE and IgG were prepared as three-fold serial dilutions of a sera pool collected from a single allergic horse before initiation of immunotherapy and known to be highly reactive to grass pollens. The reactivity of these calibrators to a mixture of grass pollen allergens was determined in each of the respective assay runs. The expected background corrected values for each of the IgE calibrators 1-6 was 1.317, $0.791,0.289,0.110,0.034$ and 0.000 , respectively. The expected background corrected values for each of the $\mathrm{IgG}$ calibrators $1-6$ was $3.698,1.693,0.704,0.300,0.116$ and 0.072 , respectively. For each assay, calibrator 1 was arbitrarily assigned a relative concentration value of 100 units and calibrators 2-6 were assigned concentration values based upon dilution.

\section{ELISA procedure ( $\lg E$ and $\lg G$ )}

The sera samples were evaluated separately for IgE and IgG with a panel of allergens including five mites, 16 grasses, 19 trees, 14 weeds, 13 fungi, 11 insects and two environmental allergens/epithelial extracts (Table S1) using enzyme linked immunosorbent assays (ELISA). All secondary antibodies were purchased from Immunology Consultants Laboratory, Inc. (Portland, OR, USA), then biotinylated following previously reported procedures. ${ }^{15-17}$ For specificity, the 
monoclonal anti-IgE and anti-IgG antibodies (IgG-Kappa) were purified from tissue culture using protein $A$ chromatography and were shown to react with horses $\operatorname{IgE}$, but not $\operatorname{Ig} \mathrm{M}, \operatorname{Ig} A$ or IgG (data not published). The ELISA procedures for IgE and IgG used have been previously described. ${ }^{15-17}$ Results were expressed as ELISA absorbance units (EAU), which are background corrected responses expressed as milliabsorbance. Potential responses range from 0 to 4,000 EAU and the positive-negative cut-off EAU values for the assays was determined to be 150 EAU.

\section{Allergen-specific immunotherapy (ASIT)}

Horses were randomly assigned to ASIT treatment groups in blocks of three to minimize the potential effects of season and environmental conditions when the ASIT was initiated. Order of assignment within each block was randomized a priori. ASIT was formulated based on IDT results alone (Group 1; $n=7$ ); allergen-specific IgE results by ELISA (Group 2; $n=6$ ); or a composite of IDT and ELISA results (Group $3 ; n=6$ ). Immunotherapy regimens consisted of the allergens specific to each horse's test reactivity which were diluted in a sterile aqueous vehicle ( $0.9 \%$ sodium chloride, $0.4 \%$ phenol) at a final concentration of 20,000 protein nitrogen units $/ \mathrm{ml}$. Based on the number of positive reactions observed with testing results, horses were given a single vial of ASIT if less than 15 allergens were to be included and a dual vial if greater than 15 allergens were to be included in the ASIT. Non-insect environmental allergens, aeroallergens as well biting fly allergen were added to the ASIT based on reactivity. Owners initiated ASIT for each horse. After a six week induction period of gradual dose increase by subcutaneous injection, the standard maintenance protocol adopted was $1 \mathrm{ml}$ of allergen admixture every 21 days for single vial ASIT, and $1 \mathrm{ml}$ alternating between vial $A$ and vial $B$ at ten day intervals for dual vial ASIT. All horses in this study were also allowed supplemental oral or systemic medications when indicated by the owner or attending veterinarian.

\section{Clinical evaluations}

A ten-point (0-10) visual analog scale (VAS) was used to provide assessment of clinical disease by the horse owner and the primary investigator at enrolment, time zero and after 12 and 24 months during ASIT by the owner via email or telephone. The owner was instructed to mark within this scale where they would place the horse's comfort/clinical signs since starting ASIT. Horses which scored at the low end of the scale experienced no itching or demonstrable skin lesions, such as hives, and appeared normal. Horses which scored at the high end of the scale presented with severe pruritus and excoriations, and/or recurrent urticarial that disrupted daily activity. Owners were instructed at each VAS evaluation to record any adverse reactions noted to the ASIT as well as any concurrent anti-pruritic therapies used. The primary investigator communicated with horse owners regarding clinical signs, change in medications and adjusted for any adverse reactions to ASIT throughout the duration of the study. At the conclusion of the study, owners of horses that had completed the entire 24 month trial provided an exit survey

This article is protected by copyright. All rights reserved 
with a "global assessment" score (GAS) which accounted for owner's overall satisfaction with clinical improvement, decrease in overall concurrent medications and desire to continue the ASIT.

\section{Statistical analysis}

All analyses were conducted in Stata 12 (StataCorp LLC, College Station, TX, USA). Visual analog scores at each point of assessment were expressed as means and $95 \%$ confidence intervals. To determine if VAS scores improved across all horses from time 0 (enrolment) to the time of study conclusion (24 months), generalized least squares logistic regression analysis was utilized. To determine if the type of test used to formulate ASIT was correlated with improvement of VAS scores, the Kruskal Wallis test was utilized and the potential influence of seasonality on VAS scores was tested with multinomial logistic regression. Spearman's rank test of association was used to detect correlations between immediate and delayed IDT reactions and ELISA scores at time zero. To assess whether allergen-specific [IgE] and [IgG] varied over time, according to the allergen's inclusion in the ASIT vaccines, repeated measures panel regression was utilized. Finally, to determine if horses reacted to groups of related allergens that have previously been documented to exhibit cross-reactivity in atopic humans or dogs, Fisher's exact test for association was utilized. A $P$-value of $\leq 0.05$ was used to denote statistical significance for all outcomes.

\section{Results}

A total of 19 horses with clinical signs consistent with a diagnosis of atopic dermatitis were enrolled in the study. There were 11 gelded males and eight intact females representing various breeds (Table 1), which ranged in age from two years to 22 years (mean 12.3 years). Eight horses were diagnosed with pruritus alone, three with recurrent/non-pruritic urticaria, seven with recurrent urticaria and pruritus, and one with pruritus and eosinophilic collagenolytic granulomas. Clinical signs were assessed as either seasonal $(n=14)$ or perennial with seasonal exacerbations $(n=5)$. The five horses in the latter category were reactive to both seasonal aeroallergens (pollens) and non-seasonal allergens (dust mites/moulds) and had a history of significant exacerbation of clinical signs with seasonal changes. The minimum number of positive reactions on IDT for any individual horse was six. Seventeen of the horses had at least one biting insect on the ASIT (range 1-9 insect allergens, average 5.47). The remaining two horse had two non-biting insects (May fly and moth) in the ASIT.

Attrition was experienced across all treatment groups. However, loss of specific horses to the study was not related solely to immunotherapy failure and all horses that completed the 12month and 24-month evaluation were included in all statistical analyses. Seventeen horses completed the first year and 11 horses the second year of immunotherapy (Table 1).

This article is protected by copyright. All rights reserved 
The mean VAS score across the 19 horses at the time of study enrolment was 6.44. Despite randomization, Group 2 had a significantly lower VAS score ( mean $=5.17$ ) at baseline than the IDT group ( mean $=6.14 ; p<0.001$ ) and the combination test group ( mean $=8.0 ; p=0.0001)$. The very low value from a single horse appeared to influence the Group 2 mean VAS at baseline; when this horse was excluded from the analysis, the Group 2 VAS was 6.2 and not significantly different from the other groups.

Overall, owner-assessed clinical improvement was evident in 13 of the 17 horses $(76.5 \%)$ that completed the first 12 months of ASIT, whereas no substantial clinical benefit was noted in the remaining four animals. After 24 months of therapy, nine of $11(81.8 \%)$ were judged to have benefitted from the ASIT. All horses assigned to either Groups 2 or 3 achieved clinical improvement; however, only two of four (50\%) horses in group 1 showed similar clinical improvement. Using least squares logistic regression analysis, the mean VAS score was shown to decrease across the entire cohort by 1.2 units [95\% Cl: $-1.275,-1.143 ;(p<0.0001)]$ for each 12 month period of ASIT therapy, resulting in a total of 2.4 units improvement at the conclusion of the study. However, the majority of improvement in VAS scores was actually realized during the first 12 month period of ASIT in all groups, with only Groups 2 and 3 having additional improvement in VAS score by the 24 month end-point. Seasonality of clinical signs was not statistically associated with the outcome measure of VAS at either 12 or 24 months $(p=0.984$ and $p=0.659$, respectively). There was also no statistical difference in clinical response between horses that received treatment from a single vial versus two treatment vials.

An overall decrease in concomitant use of anti-pruritic therapies was noted with ASIT therapy. At study onset, nine of 19 horses (47\%) were receiving oral and/or topical treatment for control of their AD when ASIT was first initiated (Table 1). At the conclusion of the study, three horses $(27 \%)$ required additional anti-pruritic therapy, while eight of $11(73 \%)$ horses completing the study did not receive or require additional anti-pruritic therapy. Of the three that continued to require adjunctive treatment, two received occasional oral corticosteroids to provide some additional relief of clinical signs, whereas the third horse received oral antihistamines (cetirizine) seasonally. Two of these three horses had a favourable global assessment score (GAS) and continued on ASIT at the conclusion of the study. Overall, nine of 11 horses that completed the 24 month assessment were deemed to have a positive GAS and continued on ASIT after study close-out.

Five adverse reactions were reported by the owners to the primary investigator throughout the 24 month treatment period. Four cases (horses 1, 16, 18 and 19) developed localized reactions at their ASIT injection sites during the induction phase but resolved with adjustment in ASIT

This article is protected by copyright. All rights reserved 
dose volume. The remaining case (horse 12) had prolonged tube clotting times noted at subsequent blood sampling time points.

There was excellent positive correlation between allergen-specific IgE concentrations [IgE] determined at the initiation of the study and the immediate IDT reactions $(p<0.00001)$ as well as the delayed IDT reactions $(p<0.00001)$. There was also excellent positive correlation between allergen-specific IgG concentrations [IgG] determined at Time 0 and the immediate IDT reactions $(p=0.0003)$, but not between serum $[\mathrm{IgG}]$ and delayed IDT reactions $(p=0.269)$.

Following prolonged ASIT (at the 12 month evaluation) concentrations of allergen-specific IgE were reduced 5-10x initial levels $(p<0.05)$ and remained at these lower levels throughout the remainder of the study period. For most horses, allergen-specific [ $\mathrm{IgG}$ ] initially increased between two to four times the initial levels, waned slightly, then remained at levels higher than baseline for the remainder of the evaluation period (Table S2). In a minority of horses, allergenspecific [IgG] remained relatively constant throughout the course of treatment (Table S3).

When groups of allergens known to be cross-reactive were analysed for co-reactivity based on equine IDT and allergen-specific IgE responses, ${ }^{18,19}$ there were highly significant correlations. These were noted for co-reactivity as assessed by immediate IDT $(p<0.0001)$, delayed IDT $(p<0.0001)$ and $\operatorname{lgE}$ scores $>150$ EAU $(p=0.008)$. Weed pollens known to cross-react in other species ${ }^{18}$ had significant correlation across immediate IDT, delayed IDT and ELISA. Dust mites cross-reactivity $^{19}$ also showed significant correlation across immediate IDT, delayed IDT and ELISA; while storage mite reactivity correlated only between immediate and delayed IDT (Table 2).

\section{Discussion}

Results of this study support the hypothesis that a favourable response to ASIT in horses is associated with decreased concentrations of allergen-specific IgE and steady to increased concentrations of allergen-specific IgG over time. These results could be consistent with a regulatory $\mathrm{T}$-cell effect on both IgE and IgG production, induced by $\mathrm{ASIT}^{20,21}$

A major objective of this study was to compare the clinical responses of horses to ASIT that was formulated based on different types of allergen screening tests (IDT versus ELISA). Previous studies have demonstrated poor correlation between IDT and serological testing results in horses, and when IDT was used as the "gold standard", serological tests suffered from poor sensitivity and marginal specificity. ${ }^{11,19}$ However, the reverse would be true if serological test results were used as the reference standard. One retrospective study found no significant difference in response rates or time of response of horses to ASIT regardless of the test

This article is protected by copyright. All rights reserved 
modality used for ASIT formulation. ${ }^{12}$ The results of the current prospective longitudinal evaluation are consistent with these observations, as significant differences in outcomes were not detected regardless of the testing modality used for allergen selection. There was also excellent agreement between serum allergen-specific [ $\mathrm{IgE}]$ and both immediate and delayed IDAT reactions. Therefore, we propose that either test can be used to select allergens for ASIT.

We also analysed our data for evidence of cross-reactivity between groups of pollen and dust mite allergens that are known to be cross-sensitizing in other species. ${ }^{18,19}$ The allergen groups chosen for analysis consisted of only those that were tested on both the IDT and ELISA panels. There were highly significant correlations within each group as assessed by both immediate and delayed IDT reactions and by the IgE assay. Although true allergen cross-reactivity is best assessed by ELISA inhibition assays, it was believed in our study that true cross-reactivity occurred based on the highly statistically significant values achieved; these values would be unlikely based on chance alone. Therefore, these findings support the use of allergen crossreactivity data to inform the formulation of ASIT vaccines. Many horses will be multi-sensitized and there are physical limitations on how many individual allergens can be included in an allergenic mix. Knowledge of cross-reactivity can assist in selection of fewer allergens or the use of commercially available mixes.

There are several weaknesses of this study that must be considered. The lack of a validated scale for assessment of clinical signs of $A D$ in horses prompted the empirical use of a scale that was previously developed and validated for owner assessment of pruritus in $\operatorname{dog}^{22-24}$ and a previous study in horses. ${ }^{25}$ There are known weaknesses of these methods, even as applied to canine studies. ${ }^{24}$ Most notably, subjectivity and intra-observer variability might arise with this defined VAS scale. Specifically, in this study, our clinical evaluations were limited to observations made by owners/care-givers of the horses at 12 month intervals, rather than the investigators. This was due to the inability of owners to return their horses to our hospital for follow-up evaluations due to the great geographical distances the horses had to travel. The annual VAS evaluations were performed at the same season as enrolment into the study to decrease seasonal variations that exist in our geographical location. Collection of serum samples was performed by the referring veterinarians. The lack of repeated clinical evaluation by the investigators in addition to only annually recorded VAS added an element of subjectivity to our study that cannot be mitigated.

Secondly, we did not specifically rule out ARF in horses with perennial yet seasonally exacerbated signs $(n=5)$. Although AFR could cause similar clinical signs as aeroallergeninduced $A D$ or act in an additive manner to increase the pruritic threshold, we believe that the seasonal exacerbations in these case were so clinically prominent that a treatment effect from

This article is protected by copyright. All rights reserved 
ASIT could be detected. Additionally, these five horses were reactive to both seasonal aeroallergens (pollens) and non-seasonal allergens (dust mites/mould) explaining the nonseasonal yet seasonally exacerbated clinical signs. Overall there was no statistical difference in VAS scores at month 12 between horses with strictly seasonal clinical signs and those with perennial disease. However, at 24 months, three of five horses with perennial disease had been lost to follow up. In the remaining two horses, overall clinical signs, especially seasonal exacerbation, had improved resulting in owners continuing immunotherapy.

Thirdly, we cannot rule out the possibility that concurrent insect hypersensitivity affected our results. Seventeen of 19 horses had biting insect allergens included in their ASIT formulas. The efficacy of ASIT for equine IH has not been adequately addressed by randomized, controlled trials and inclusion of these subjects may have confounded results. In addition, horse owners were educated on how to improve biting fly avoidance strategies. Due to the high proportion of horses that are co-sensitized to aeroallergens and biting insect allergens in our region, it would not have been possible to conduct this study if horses with $\mathrm{IH}$ were excluded. Yet, our results were consistent at the 12 month evaluation with other studies that have shown a noticeable clinical response to $A S I T$ for pruritic horses with $A D,{ }^{26}$ horses with urticaria ${ }^{27}$ and horses with combined $A D$ and $I H .{ }^{25}$

In spite of these limitations, measurable benefit was noted in most horses during the first 12 months of ASIT. Overall, clinical improvement of VAS within the first year following the initiation of ASIT was noted in $76.5 \%$ of the horses treated and increased to nearly $82 \%$ with continuation of ASIT for an additional year, despite four horses that were improved after 12 months were subsequently lost to follow-up. The response rates observed in this study are consistent with, but greater than the response rates previously reported for ASIT as a sole therapy for pruritus in horses ${ }^{12}$ and less than the $92 \%$ response rate reported for recurrent urticaria in horses. ${ }^{26}$ The treatment effect measured in this study appeared to have not been influenced by the seasonality of clinical signs or the number of allergens included in ASIT. Because of substantial overlap in clinical signs in individual horses combined with the limited number of horses with only non-pruritic urticaria in this study, we did not perform a pruritus versus urticaria sub-group analysis.

Four horses (horse 1, 16, 18, 19) demonstrated adverse events associated with ASIT during the induction protocol. The adverse event was characterized by localized swelling or hive formation at the injection site which when ASIT dosing was adjusted resolved and horses continued in the study. These cases highlight the importance of regular client communication during ASIT induction protocols, as these horses may not have continued therapy to assess response without vaccine adjustments. The remaining adverse reaction in horse 12 (clotting disorder) 
was unexpected. This horse had no clinical abnormalities noted by the owner and was responding exceptionally well to the ASIT with complete resolution of the pruritus and eosinophilic granulomas (after failing a prior ASIT protocol based on serological testing prior to referral). Upon repeated blood sampling for IgE and IgG serology, a prolonged clotting time was noted in the serum separator tube. Haematological testing was performed and no significant clotting dysfunction was identified. However, when ASIT was temporarily discontinued and repeat sampling was performed, tube clotting time returned to normal. When ASIT was restarted, the abnormality was repeatable. Since this horse was used for longdistance competitive trail riding, the owners elected to permanently discontinue ASIT despite improvement in clinical signs. To the best of the authors' knowledge, no similar, repeatable clotting disorders have been reported in any species with ASIT therapy.

In conclusion, the results presented herein demonstrate that most horses completing a minimum of 12 months on ASIT will have a favourable response that prompts owners to continue with therapy. The type of test used to select allergens for inclusion in the ASIT vaccine did not appear to influence outcome in this study population. Local (injection site) reactions are relatively common in horses and respond to dose adjustments. Successful ASIT in horses is associated with reduction of allergen-specific [IgE] and either increased or steady levels of allergen-specific [IgG], which could theoretically be associated with a T regulatory cell response as described in other species. Randomized/controlled clinical trials in horses with the use of a validated scale for assessment of clinical signs of $A D$ in horses are needed to better characterize the clinical and immunological responses to ASIT.

\section{References}

1. Wagner B, Miller WH, Morgan EE, et al. IgE and IgG antibodies in skin allergy of the horse. Vet Res 2006; 37: 813-825.

2. Wilson AD, Hardwood LJ, Bjornsdottir $S$, et al. Production of monoclonal antibodies specific for native equine IgE and their application to monitor total serum IgE responses in Icelandic and non-Icelandic horses with insect bite dermal hypersensitivity. Vet Immunol Immunopathol 2006; 112: 156-170.

3. Wagner B, Miller WH, Hollis NE, et al. Sensitization of skin mast cells with IgE antibodies to Culicoides allergens occurs frequently in clinically healthy horses. Vet Immunol Immunopathol 2009; 132: 53-61.

4. Wagner B, Overesch G, Sheoran AS, et al. Organization of equine immunoglobulin heavy chain constant region genes; III. Alignment of c mu, c gamma, c epsilon, c alpha genes.

This article is protected by copyright. All rights reserved 
Immunobiology 1998; 199: 105-118.

5. Wagner B, Greiser-Wilke I, Wege A, et al. Evolution of the six horse IGHG genes and corresponding immunoglobulin gamma heavy chains. Immunogenetics 2002; 54: 353-364.

6. Lewis MJ, Wagner B, Woof JM. The different effector function capabilities of the seven equine IgG subclasses have implications for vaccine strategies. Mol Immunol 2008; 45: 818-827.

7. Wagner B, Miller DC, Lear TL, et al. The complete map of the Ig heavy chain constant region reveals evidence for seven IgG isotypes and for IgD in the horse. J Immunol 2004; 173: $3,230-3,242$.

8. Keggan A, Freer H, Rollins A, et al. Production of seven monoclonal equine immunoglobulins isotyped by multiplex analysis. Vet Immunol Immunopathol 2013; 153: 187-193.

9. Morgan EE, Miller WH, Wagner B. A comparison of intradermal testing and detection of allergen-specific immunoglobulin $E$ in serum by enzyme-linked immunosorbent assay in horses affected with skin hypersensitivity. Vet Immunol Immunopathol 2007; 120: 160-167.

10. Kalina WV, Pettigrew HD, Gershwin LJ. IgE ELISA using antisera derived from epsilon chain antigenic peptides detects allergen-specific $\mathrm{IgE}$ in allergic horses. Vet Immunol Immunopathol 2003; 92: 137-147.

11. Lorch G, Hillier A, Kwochka KW, et al. Comparison of immediate intradermal test reactivity with serum IgE quantitation by use of a radioallergosorbent test and two ELISA in horses with and without atopy. J Am Vet Med Assoc 2001; 218: 1,314-1,322.

12. Stepnik CT, Outerbridge CA, White SD, et al. Equine atopic skin disease and response to allergen-specific immunotherapy: a retrospective study at the University of California-Davis (1991-2008). Vet Dermatol 2012; 23: 29-35.

13. Keppel KE, Campbell KL, Zuckermann FA, et al. Quantification of canine regulatory T-cell populations, serum interleukin-10 and allergen-specific IgE concentrations in healthy control dogs and canine atopic patients receiving allergen-specific immunotherapy. Vet Immunol Immunopathol 2008; 123: 332-344.

14. Scott DW, Miller WH. Equine Dermatology. Philadelphia, PA: Saunders, 2003: 453-458.

This article is protected by copyright. All rights reserved 
15. Lee KW, Blankenship KD, McCurry ZM, et al. Performance characteristics of a monoclonal antibody cocktail-based ELISA for detection of allergen-specific IgE in dogs and comparison with a high affinity IgE receptor-based ELISA. Vet Dermatol 2009; 20: 157-164.

16. Lee KW, Blankenship KD, McCurry ZM, et al. Intra and inter-laboratory reproducibility of a monoclonat antibody cocktail based ELISA for detection of allergen specific IgE in dogs: proficiency monitoring of macELISA in six laboratories. Vet Immunol Immunopathol 2012; 148: 267-275.

17. McKinney B, Blankenship K Lee K. Development and Characterization of a Single Enzyme Linked Immunosorbent Assay for Detection of Antigen Specific IgG in Both Dogs and Cats. Integr J Vet Biosci 2018; 2: 1-15.

18. Buckley L, Schmidt V, McEwan N, et al. Cross-reaction and co-sensitization among related and unrelated allergens in canine intradermal tests. Vet Dermatol 2013, 24: 422-421.

19. Saridomichelakis MN, Marsella R, Lee KW, et al. Assessment of cross-reactivity among five species of house dust and storage mites. Vet Dermatol 2008; 19: 67-76.

20. Bussman $C$, Bockennoff $A$, Henke $H$, et al. Does allergen- specific immunotherapy represent a therapeutic option for patients with atopic dermatitis? J Allergy Clin Immunol 2006; 118: $1,292-1,298$.

21. Crameri R, Rhyner C. Novel vaccines and adjuvants for allergen-specific immunotherapy. Curr Opin Immunol 2006; 18: 761-768.

22. Hill PB, Lau P, Rybnicek J. Development of an owner-assessed scale to measure the severity of pruritus in dogs. Vet Dermatol 2007; 18: 301-308.

23. Rybnícek J, Lau-Gillard PJ, Harvey R, et al. Further validation of a pruritus severity scale for use in dog. Vet Dermatol 2008; 20: 115-122.

24. Plant JD. Repeatability and reproducibility of numerical rating scales and visual analogue scales for canine pruritus severity scoring. Vet Dermatol 2007; 18: 294-300.

\section{Rosenkrantz WS, Griffin CE, Esch RE, et al. Responses in}

This article is protected by copyright. All rights reserved 
horses to intradermal challenge of insects and environmental allergens with specific immunotherapy. In: Kwochka KW, Willemse T, von Tscharner C, eds. Advances in veterinary dermatology. Oxford,

England: Butterworth-Heinemann, 1998;191200.

Rosenkrantz WS, Griffin CE, Esch RE, et al. Responses in

horses to intradermal challenge of insects and environmental allergens with specific immunotherapy. In: Kwochka KW, Willemse T, von Tscharner C, eds. Advances in veterinary dermatology. Oxford, 


\section{England: Butterworth-Heinemann, 1998;191- 200.}

25. Rosenkrantz WS, Griffin CE, Esch RE, et al. Responses in horses to intradermal challenge of insects and environmental allergens with specific immunotherapy. In: Kwochka KW, Willemse T, von Tscharner C, eds. Advances in Veterinary Dermatology, volume 3. Oxford, England: Butterworth-Heinemann, 1998; 191-200.

26. Tallarico NJ, Montesano-Tallarico $C$. Results of intradermal allergy testing and treatment by hyposensitization of 64 horses with chronic obstructive pulmonary disease, urticaria, headshaking, and/or reactive airway disease. Vet Allergy and Clin Immunol 1998; 6: 25-35.

27. Rees C. Response to immunotherapy in six related horses with urticaria secondary to atopy. J Am Vet Med Ass 2001; 218: 753-755.

Table 1 Metadata for 19 horses enrolled in the allergen-specific immunotherapy study

\begin{tabular}{|c|c|c|c|c|c|c|c|c|c|c|c|}
\hline \multirow[t]{2}{*}{$\begin{array}{l}\text { Hors } \\
\text { e }\end{array}$} & \multirow{2}{*}{ Breed } & \multirow{2}{*}{$\begin{array}{l}\text { Age } \\
\text { (years } \\
\text { ) }\end{array}$} & \multirow[t]{2}{*}{$\begin{array}{l}\text { Se } \\
x\end{array}$} & \multirow[t]{2}{*}{$\begin{array}{l}\text { Clinical } \\
\text { signs }\end{array}$} & \multirow[t]{2}{*}{ Treatments } & \multicolumn{3}{|c|}{$\begin{array}{l}\text { Visual analog scale } \\
\text { score }\end{array}$} & \multicolumn{2}{|c|}{$\begin{array}{l}\text { Global } \\
\text { Assessment }\end{array}$} & \multirow{2}{*}{$\begin{array}{l}\text { Group } \\
\text { Numbe } \\
r\end{array}$} \\
\hline & & & & & & 0 & $\begin{array}{l}12 \\
\text { month } \\
\mathrm{s}\end{array}$ & $\begin{array}{l}24 \\
\text { month } \\
\mathrm{s}\end{array}$ & $\begin{array}{l}12 \\
\text { month } \\
\mathrm{s}\end{array}$ & $\begin{array}{l}24 \\
\text { month } \\
\mathrm{s}\end{array}$ & \\
\hline 1 & $\begin{array}{l}\text { Welsh } \\
\text { pony }\end{array}$ & 17 & $\mathrm{FI}$ & $\begin{array}{l}\text { non- } \\
\text { pruritic } \\
\text { RU; (S) }\end{array}$ & None Known & 7 & 4 & 4 & 0 & 0 & 1 \\
\hline 2 & $\begin{array}{l}\text { Andalusia } \\
\mathrm{n} \text { cross }\end{array}$ & 18 & MC & $\begin{array}{l}\text { pruritus } \\
;(\mathrm{S})\end{array}$ & None Known & 4 & 1 & 0 & 1 & 1 & 2 \\
\hline 3 & $\begin{array}{l}\text { Draft } \\
\text { cross }\end{array}$ & & MC & $\begin{array}{l}\mathrm{RU}+ \\
\text { pruritus } \\
;(\mathrm{S})\end{array}$ & $\begin{array}{l}\text { anti-pruritic } \\
\text { shampoo }\end{array}$ & 9 & $\overline{N A}$ & $\overline{N A}$ & NA & $\overline{N A}$ & 3 \\
\hline $4^{\dagger}$ & $\begin{array}{l}\text { Arabian } \\
\text { cross }\end{array}$ & 13 & $\mathrm{FI}$ & $\begin{array}{l}\text { pruritus } \\
;(S)\end{array}$ & None Known & $\begin{array}{l}1 \\
0\end{array}$ & 7 & 2 & 1 & 1 & 1 \\
\hline 5 & Morgan & 22 & MC & $\begin{array}{l}\mathrm{RU}+ \\
\text { pruritus } \\
;(\mathrm{S})\end{array}$ & $\begin{array}{l}\text { anti-pruritic } \\
\text { shampoo and } \\
\text { oral } \\
\text { hydroxyzine }\end{array}$ & 7 & 7 & 3 & 1 & 1 & 2 \\
\hline
\end{tabular}

This article is protected by copyright. All rights reserved 


\begin{tabular}{|c|c|c|c|c|c|c|c|c|c|c|c|}
\hline 6 & $\begin{array}{l}\text { Quarter } \\
\text { horse }\end{array}$ & 20 & MC & $\begin{array}{l}\text { pruritus } \\
;(P)\end{array}$ & $\begin{array}{l}\text { oral } \\
\text { prednisone } \\
\text { and } \\
\text { hydroxyzine }\end{array}$ & $\begin{array}{l}1 \\
0\end{array}$ & 9 & NA & 0 & NA & 3 \\
\hline 7 & $\begin{array}{l}\text { Andalusia } \\
\mathrm{n} \text { cross }\end{array}$ & 2 & Ml & $\begin{array}{l}\text { pruritus } \\
;(\mathrm{S})\end{array}$ & $\begin{array}{l}\text { oral } \\
\text { hydroxyzine }\end{array}$ & 7 & 6 & 3 & 1 & 1 & 1 \\
\hline $8^{\dagger}$ & Arabian & 10 & $\mathrm{FI}$ & $\begin{array}{l}\mathrm{RU}+ \\
\text { pruritus } \\
;(\mathrm{S})\end{array}$ & $\begin{array}{l}\text { anti-pruritic } \\
\text { shampoo }\end{array}$ & 6 & 3 & 2 & 1 & 1 & 2 \\
\hline 9 & $\begin{array}{l}\text { Quarter } \\
\text { horse }\end{array}$ & 22 & $\mathrm{FI}$ & $\begin{array}{l}\text { non- } \\
\text { pruritic } \\
\text { RU; (S) }\end{array}$ & $\begin{array}{l}\text { oral } \\
\text { dexamethason } \\
\text { e q } 4 \text { days }\end{array}$ & 7 & 0 & 1 & 1 & 1 & 3 \\
\hline $10^{\dagger}$ & $\begin{array}{l}\text { Thoroug } \\
\text { bred }\end{array}$ & & $\mathrm{FI}$ & $\begin{array}{l}\mathrm{RU}+ \\
\text { pruritus } \\
;(\mathrm{P})\end{array}$ & None Known & 1 & 0 & $\overline{N A}$ & 1 & Euth & 1 \\
\hline 11 & $\begin{array}{l}\text { Thorough- } \\
\text { bred }\end{array}$ & 10 & MC & $\begin{array}{l}\text { pruritus } \\
;(\mathrm{S})\end{array}$ & None Known & 8 & 2 & NA & 1 & NA & 2 \\
\hline $12^{\dagger}$ & Fox trotte & 6 & $\mathrm{FI}$ & $\begin{array}{l}\text { pruritus } \\
+\quad E G ; \\
\text { (S) }\end{array}$ & None Known & $\begin{array}{l}1 \\
0\end{array}$ & 7 & NA & 1 & NA & 3 \\
\hline 13 & Nakota & & MC & $\begin{array}{l}\mathrm{RU}+ \\
\text { pruritus } \\
;(\mathrm{S})\end{array}$ & None Known & 7 & 5 & 7 & 0 & 0 & 1 \\
\hline 14 & $\begin{array}{l}\text { Thorough } \\
\text { bred }\end{array}$ & & MC & $\begin{array}{l}\mathrm{RU}+ \\
\text { pruritus } \\
;(\mathrm{S})\end{array}$ & $\begin{array}{l}\text { unspecified } \\
\text { anti-pruritic } \\
\text { therapy }\end{array}$ & $\overline{0}$ & $\overline{N A}$ & $\overline{N A}$ & NA & $\overline{N A}$ & 2 \\
\hline 15 & $\begin{array}{l}\text { Tennessee } \\
\text { Walker }\end{array}$ & 13 & MC & $\begin{array}{l}\text { pruritus } \\
;(S)\end{array}$ & None Known & 7 & 2 & 4 & 1 & 1 & 3 \\
\hline 16 & $\begin{array}{l}\text { Thorough } \\
\text { bred }\end{array}$ & & MC & $\begin{array}{l}\text { pruritus } \\
; \\
\text { (S) }\end{array}$ & $\begin{array}{l}\text { anti-pruritic } \\
\text { shampoo }\end{array}$ & 3 & 3 & $\overline{N A}$ & 0 & NA & 1 \\
\hline 17 & $\begin{array}{l}\text { Quarter } \\
\text { horse }\end{array}$ & 6 & MC & $\begin{array}{l}\mathrm{RU}+ \\
\text { pruritus } \\
;(\mathrm{P})\end{array}$ & None Known & 6 & 0 & 3 & 1 & 1 & 2 \\
\hline 18 & Morgan & 7 & $\mathrm{FI}$ & $\begin{array}{l}\text { pruritus } \\
;(\mathrm{P})\end{array}$ & $\begin{array}{l}\text { oral cetirizine } \\
\text { and } \\
\text { prednisone } \\
\text { daily }\end{array}$ & 5 & 6 & 5 & 1 & 1 & 3 \\
\hline 19 & $\begin{array}{l}\text { Hanovaria } \\
\mathrm{n}\end{array}$ & 12 & $\mathrm{FI}$ & $\begin{array}{l}\text { non- } \\
\text { pruritic } \\
\text { RU; (P) }\end{array}$ & None Known & 8 & 3 & $\overline{N A}$ & 1 & $\overline{N A}$ & 1 \\
\hline
\end{tabular}

MC castrated male; FI intact female; S seasonal; $\mathrm{P}$ perennial with seasonal exacerbation; RU recurrent urticaria; EG eosinophilic granuloma; Euth euthanized. 
$†$ Horses which were previously receiving ASIT based on serological testing prior to study enrolment with no clinical benefit/response

Global assessment score 0 no improvement/discontinued allergen-specific immunotherapy (ASIT); $1 \mathrm{improved/continued} \mathrm{ASIT}$

Group 1 ASIT selected from intradermal test (IDT) results

Group 2 ASIT selection from ELISA results

Group 3 ASIT selected from combination of IDT and ELISA results

Table 2 Allergen cross-reactivity as assessed by intradermal testing and ELISA

\begin{tabular}{|l|l|l|l|}
\hline Allergen group & IDT Imm ediate & IDT Delayed & ELISA $>150$ \\
\hline $\begin{array}{l}\text { Meadow fescue (Festuca pratensis), } \\
\text { perennial rye (Lolium perenne), sweet vernal } \\
\text { (Anthoxanthum odoratum) }\end{array}$ & p value & p value & p value \\
\hline $\begin{array}{l}\text { 2 Tree pollens } \\
\text { Beech (Fagus grandifolia), birch mix (Betula } \\
\text { nigra, B. populifolia, B. lenta, oak mix } \\
\text { (Quercus velutina, Q. rubra, Q. alba) }\end{array}$ & 0.1748 & $0.018^{*}$ & 0.368 \\
\hline $\begin{array}{l}3 \text { Weed pollens } \\
\text { Cocklebur (Xanthium strumarium), ragweed } \\
\text { mix (Ambrosia trifida, A. artemisiifolia) }\end{array}$ & 0.5 & $<0.001^{*}$ & $0.021^{*}$ \\
\hline $\begin{array}{l}4 \text { Mites } \\
\text { Acarus siro, Dermatophagoides farinae, } \\
\text { Tyrophagus putrescentiae }\end{array}$ & 0.169 & 0.066 & 0.063 \\
\hline $\begin{array}{l}5 \text { Mites } \\
\text { D. pteronyssinus, Lepidoglyphus destructor }\end{array}$ & $0.007^{*}$ & 0.125 & 0.368 \\
\hline $\begin{array}{l}6 \text { Storage mites } \\
\text { A. siro, T. putrescentiae, L. destructor }\end{array}$ & 0.368 & 0.459 & $<0.001^{*}$ \\
\hline $\begin{array}{l}7 \text { Dust mites } \\
\text { D. farinae, D. pteronyssinus }\end{array}$ & 1.0 & 1.0 & 0.5 \\
\hline
\end{tabular}

* Significant $p$ value

Concordance of reactivity to groups of related allergens is reported according to test type: Immediate and delayed responses to intradermal testing (IDT) and ELISA results. A significant

This article is protected by copyright. All rights reserved 
$p$ value indicates discordance, lack of correlation $\left({ }^{*}\right)$, of results within the group of allergens tested.

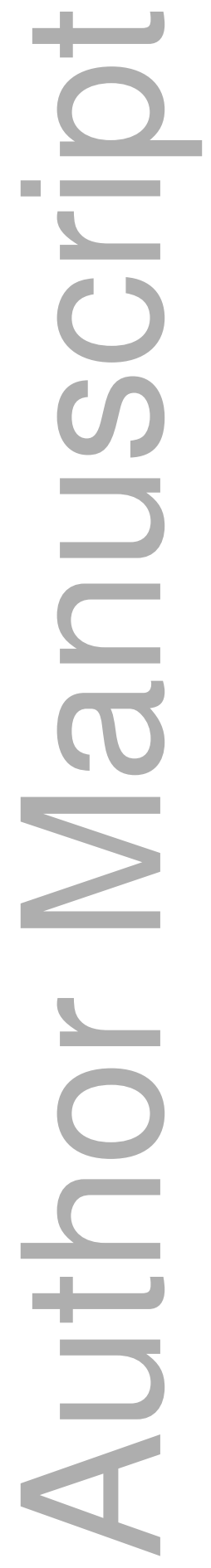

This article is protected by copyright. All rights reserved 


\section{University Library}

\section{- M I I N E R VA \\ A gateway to Melbourne's research publications}

Minerva Access is the Institutional Repository of The University of Melbourne

Author/s:

Radwanski, NE;Morris, DO;Boston, RC;Cerundolo, R;Lee, KW

Title:

Longitudinal evaluation of immunological responses to allergen-specific immunotherapy in horses with IgE associated dermatological disease, a pilot study.

Date:

2019-06

Citation:

Radwanski, N. E., Morris, D. O., Boston, R. C., Cerundolo, R. \& Lee, K. W. (2019). Longitudinal evaluation of immunological responses to allergen-specific immunotherapy in horses with IgE associated dermatological disease, a pilot study.. Vet Dermatol, 30 (3), pp.255-e78. https://doi.org/10.1111/vde.12732.

Persistent Link:

http://hdl.handle.net/11343/285551 